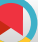

\title{
Professional Socialization of Nursing Students and Its Relationship with Self-Esteem
}

\author{
Maasoumeh Barkhordari-Sharifabad (iD ${ }^{1,{ }^{*}}$ and AliAskar Mortazavi (iD) ${ }^{1}$ \\ ${ }^{1}$ Department of Nursing, School of Medical Sciences, Yazd Branch, Islamic Azad University, Yazd, Iran \\ "Corresponding author: Department of Nursing, School of Medical Sciences, Yazd Branch, Islamic Azad University, 8916871967, Yazd, Iran. Email: barkhordary.m@gmail.com
}

Received 2021 July 23; Revised 2021 October 10; Accepted 2021 November 09.

\begin{abstract}
Background: Nursing students must have the desired level of professional socialization to acquire the necessary roles and values to participate in the health care system. The process of socialization is part of the self-concept.

Objectives: The aim of this study was to determine the level of socialization of nursing students and its relationship with selfesteem.

Methods: This was a cross-sectional descriptive study. Data were collected from 166 nursing students. Data collection tools were demographic, professional socialization, and self-esteem questionnaires. The collected data were analyzed using descriptive and inferential statistical methods by SPSS 16.

Results: The average scores of professional socialization and self-esteem were $174.87 \pm 19.5$ and $5.65 \pm 5.10$, respectively. Professional socialization was moderate in the majority of the participants (54.80\%). The dimensions of "valuation and knowledge of the profession" and "management and organizational policies" had the highest and lowest averages, respectively. There was a positive and significant relationship between professional socialization and all its dimensions with self-esteem $(\mathrm{P}<0.05)$. Also, there was a significant relationship between "professional socialization" and "interest in the field" as well as "the adaptation of the field to the ideas after entering the university".

Conclusions: By considering strategies, such as creating a positive attitude towards the nursing profession in students, professors can create a sufficient sense of self-esteem in different clinical settings and, consequently, strengthen professional socialization.
\end{abstract}

Keywords: Self-Esteem, Professional Socialization, Nursing Students

\section{Background}

Professional socialization is a complex process in which an individual acquires the knowledge, skills, and identities to become a professional and subsequently internalizes the values and norms of group behavior (1). Professional socialization is critical to the fulfillment of nurses' professional roles and the process of professional self-improvement (2). It is an extensive process from being a student to a qualified professional nurse and beyond (3). Nursing schools, clinical learning environments, and students are key components of this process (4). Acquiring professional identity, adaptation to professional roles, and professional commitment, and consequently, improving the quality of patient care are the most important positive consequences of professional socialization of nursing students $(5,6)$.

Personal factors have been mentioned as facilitators of professional socialization (3), and self-esteem is a key factor in determining personal's behaviors (7), which can predict socialization (8). According to Murk's theory, self-esteem consists of two components of competence and worthiness (9). Higher self-esteem is associated with greater interest and success in developing relationships and greater satisfaction with social relationships (8). Self-esteem is recognized as a coping source when interacting with others by strengthening individual confidence and a sense of inclusion (10). On the other hand, low self-esteem and lack of assertiveness are associated with how socialization is performed (11).

Nursing is a profession that requires a sense of responsibility, precision, and intelligence. Any shortcoming in the training of this group will certainly affect the quality of health services and ultimately, the health of individuals and communities. The main mission of nursing education is to train competent nurses who have the necessary knowledge and skills to provide high-quality nursing care (12). Self-esteem and professional socialization have a profound effect on the level of professional development 
of the individual, and better understanding is a necessary step in identifying educational strategies to improve education at universities (8). Therefore, due to a large number of nursing students from different cultures, the process of professional socialization must be carefully considered in all nursing education programs.

\section{Objectives}

The aim of this study was to determine the level of professional socialization of nursing students and its relationship with self-esteem.

\section{Methods}

This was a cross-sectional descriptive study. The population consisted of undergraduate nursing students of universities of Yazd/Iran. Considering the level of significance of $5 \%$ and test power of $80 \%$ with the assumption of $r=0.22$ (13), the sample size of 160 students was estimated using the related formula. Considering the attrition rate of $10 \%, 176$ questionnaires were distributed among eligible students. Stratified random sampling was performed according to the proportion of students in each university, considering the inclusion criteria. Inclusion criteria were a bachelor's degree in nursing, students studying in the academic year 2019-2020, passing at least one semester of clinical internship, and no transfer or guest from other educational universities.

The data collection tool was a questionnaire consisting of three parts: The first part had questions to examine individual-social characteristics, educational background, having a nursing model, having information and interest in nursing before being accepted in this field, and the reason for choosing this field.

Professional Socialization Questionnaire was designed by Bishive Moghaddam et al. (6) and was adopted from a tool developed by Shahim et al. (14) and Chao et al. (15). This 48 -item tool consisted of four categories. The total score ranged between 48 and 240 where a greater score indicated higher professional socialization. The content validity of the questionnaire was assessed using qualitative and quantitative methods, which was reported to be favorable. Cronbach's alpha coefficient and ICC of the instrument were 0.92 and 0.94 , respectively (6). In the present study, Cronbach's alpha was $87 \%$.

The Rosenberg Self-Esteem Scale (16) is one of the most widely used tools in this regard. It has 10 two-choice questions (agree and disagree), which items 1, 3, 4, 7, and 10 are positively worded, and items 2, 5, 6, 8, and 9 negatively. Scores ranged from -10 to +10 . A score above zero indicates high self-esteem, and a score below zero indicates low selfesteem. This scale has been used in many studies and has demonstrated adequate validity and reliability (17). The internal consistency reliability was confirmed by an estimated $\alpha$ of 0.93 (18).

After data collection, SPSS 16 was used for data analysis. Descriptive statistical methods (mean and standard deviation) were used to describe the data. The normal distribution of data was evaluated using Kolmogorov-Smirnov test ( $\mathrm{P}>0.05)$. Pearson's correlation coefficient was used to determine the relationship between variables. T-test and ANOVA were used to examine differences in professional socialization and self-esteem based on the characteristics of the participants.

\section{Results}

Of the 176 questionnaires distributed among students, 10 questionnaires were excluded due to being incomplete. Based on findings, the majority of nursing students were female (61.4\%) and single (86.7\%) with a mean age of 21.53 \pm 4.73 years. Also, $51.8 \%$ of students were living with their families, and $92.20 \%$ were only studying and did not have a job. The majority of the subjects expressed clinical teachers as an educational model (44.8\%) and career future (33.50\%), as well as mere acceptance in this field (33.00\%), were effective factors in choosing the field. Also, the majority of them (63.9\%) had information about the field before entering the university (Table 1 ).

Professional socialization in the majority of the participants (54.80\%) was at the moderate level, and the mean professional socialization was $174.87 \pm 19.52$. Since the number of questions in each dimension is not the same, in order to be able to calculate the weight of each dimension, all scores were converted to a ratio of 100. Thus, the highest mean was related to the field of valuation and knowledge of the profession (73.48 \pm 13.97 ), and the lowest mean was related to the field of management and organizational policies ( $57.66 \pm 11.58$ ). The mean score of self-esteem in students was $5.65 \pm 5.10$ (Table 2).

The results showed that there was a positive and significant relationship between professional socialization and its dimensions with nursing students' self-esteem $(\mathrm{P}<$ 0.05) (Table 3).

There was a significant relationship between professional socialization and interest in the field $(\mathrm{P}<0.001)$ and the adaptation of the field to perceptions after entering the university $(\mathrm{P}=0.008)$. Regarding self-esteem, this relationship was significant with the variables of acceptance in the field $(P=0.01)$ and conformity of perceptions with the realities of the field" $(\mathrm{P}=0.02)$ (Table 4$)$. 


\begin{tabular}{|c|c|}
\hline Variables & Values \\
\hline Age & $21.53 \pm 4.73$ \\
\hline \multicolumn{2}{|l|}{ Gender } \\
\hline Male & $64(38.60)$ \\
\hline Female & $102(61.40)$ \\
\hline \multicolumn{2}{|l|}{ Marital status } \\
\hline Single & $144(86.70)$ \\
\hline Married & $22(13.30)$ \\
\hline \multicolumn{2}{|l|}{ Current student residence } \\
\hline Living with family & $86(51.80)$ \\
\hline Dormitory & $74(44.60)$ \\
\hline Student house & $6(3.60)$ \\
\hline \multicolumn{2}{|l|}{ Academic year } \\
\hline First & $52(31.30)$ \\
\hline Second & $40(24.10)$ \\
\hline Third & $36(21.70)$ \\
\hline Forth & $38(22.90)$ \\
\hline \multicolumn{2}{|l|}{ Being employed while studying } \\
\hline Yes & $13(7.80)$ \\
\hline No & $153(92.20)$ \\
\hline \multicolumn{2}{|l|}{ Role model* } \\
\hline Theoretical teachers & $51(24.30)$ \\
\hline Clinical instructors & $94(44.80)$ \\
\hline Ward nurses & $50(23.80)$ \\
\hline Classmates & $15(7.20)$ \\
\hline \multicolumn{2}{|c|}{ Factors influencing the choice of nursing ${ }^{b}$} \\
\hline Acceptance in the field & $77(33.00)$ \\
\hline Career future & $78(33.50)$ \\
\hline Suggestions from others & $25(10.70)$ \\
\hline Interest & $53(22.70)$ \\
\hline \multicolumn{2}{|c|}{$\begin{array}{l}\text { Having information about the field before entering the } \\
\text { university }\end{array}$} \\
\hline Yes & $106(63.90)$ \\
\hline No & $60(36.10)$ \\
\hline \multicolumn{2}{|c|}{$\begin{array}{l}\text { Adaptation of the field to the ideas after entering the } \\
\text { university }\end{array}$} \\
\hline Yes & $66(39.80)$ \\
\hline No & $100(60.20)$ \\
\hline
\end{tabular}

\section{Discussion}

The aim of this study was to determine the degree of socialization of nursing students and its relationship with self-esteem. The results showed that the majority of students had a moderate level of professional socialization. These results are consistent with the findings of Bishive Moghaddam et al. (6). Also, a longitudinal study on nursing students in Taiwan showed that the level of professional socialization of nursing students at the three time points was moderate (19). However, this result is not consistent with some studies $(14,20,21)$, in which the level of socialization of nursing students has been reported to be high and desirable. In another study, the mean and standard deviation of the professional socialization score was $46.76 \pm 8.96$ and was at a low level (22). Differences in the results of these studies can be due to the differences in research populations and the use of different tools in determining the degree of professional socialization, which requires research using the same tools and sample size for better judgment. In addition, cultural and educational differences are other possible causes of this difference.

In the present study, the highest mean was related to the dimension of "valuation and knowledge of the profession" and the lowest mean was related to the dimension of "management and organizational policies". Consistent with this finding, the results of another study indicated that nursing students in the dimension of "management and organizational policies" were at an unfavorable level (6). Based on the results of the present study, nursing students did not have a favorable attitude toward the organization's management, nurses' authority, recognition of the role of nurses, the proportionality of responsibilities with salaries, and the importance of nurses as capable group in organizational policy. Nursing education programs should be in line with the promotion of the mentioned issues to be able to nurture students who play a professional role in providing services.

The results of the present study indicated the desired level of self-esteem, which is consistent with the findings of other studies (23-27). During the study period, the mental health of nursing students was affected in the face of problems, such as stress, hospital environment, and dealing with patients' problems. Therefore, the programs to maintain students' self-esteem should always be considered.

Our findings showed nursing students with higher self-esteem had a more desirable level of professional socialization. This finding is consistent with the results of Choi and $\mathrm{Ha}$ (13). Valizadeh et al. have introduced low selfconfidence and lack of professional independence as obstacles to professional socialization (28). Robins et al. also showed that people with high self-esteem are emotionally stable, extroverted, and conscientious to show a good degree of socialization (29). Professional socialization is a broad and complex concept and is like an umbrella that 


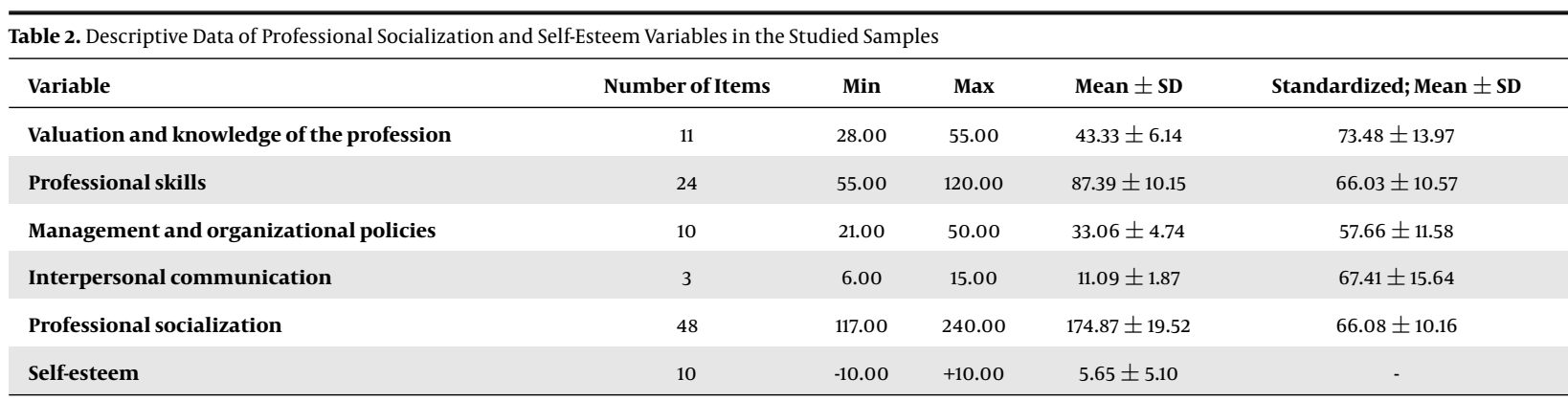

Table 3. The Relationship Between Professional Socialization and Its Dimensions with Self-Esteem

\begin{tabular}{lccc}
\hline \multirow{2}{*}{ Variables } & \multicolumn{2}{c}{ Self-Esteem } \\
\cline { 2 - 3 } & $\mathbf{r}$ & $\mathbf{P}$ \\
\hline Valuation and knowledge of the profession & 0.26 & 0.001 \\
\hline Professional skills & 0.34 & $<0.001$ \\
\hline Management and organizational policies & 0.24 & 0.002 \\
\hline Interpersonal communication & 0.28 & $<0.001$ \\
\hline Professional socialization & 0.34 & $<0.001$ \\
\hline
\end{tabular}

encompasses a set of activities related to education and homogeneity with the professional environment. The ultimate goal of professional socialization in nursing is to create a professional identity. In this study, it was found that self-esteem and its promotion and also creating a sense of worth in students can facilitate professional socialization. It seems that the role of nursing managers and educators is very important in the process of professional socialization due to the positive impact on future nurses. They can increase professional self-confidence and self-esteem by providing programs to increase students' individual abilities (knowledge, skills, and experience) and interest in the profession, and consequently, facilitate and promote professional socialization.

One of the limitations of the present study was its cross-sectional nature, which cannot support the causality of relationships. The use of self-report tools for data collection was another limitation that can affect the provision of real answers.

\subsection{Conclusion}

The majority of students have a moderate level of professional socialization, and students with higher selfesteem had a more desirable level of professional socialization. Since nursing students have an undeniable role in the care and treatment of patients in the future, planning to strengthen self-esteem and subsequently promote professional socialization has a positive effect on providing higher quality services. Therefore, by considering strategies, such as providing programs to increase students' individual abilities and interest in the profession, managers and educators can create a sufficient sense of self-esteem and, consequently, facilitate professional socialization.

It is suggested that more in-depth exploratory research be done in this regard. Also, designing studies on a broader level will lead to better insight.

\section{Footnotes}

Authors' Contribution: Study concept and design, MB$\mathrm{SH}$ and AAM; Analysis and interpretation of data, $\mathrm{MBSH}$; Drafting of the manuscript, AAM; Critical revision of the manuscript for important intellectual content, MB-SH.

Conflict of Interests: The authors declare that they have no conflicts of interests.

Data Reproducibility: The data presented in this study are openly available in one of the repositories or will be available on request from the corresponding author by this journal representative at any time during submission or after publication. Otherwise, all consequences of possible withdrawal or future retraction will be with the corresponding author.

Ethical Approval: The Ethics Committee of Islamic Azad University, Isfahan (Khorasgan) approved this study with the ethics code of ID IR.IAU.KHUISF.REC.1399.141.

Funding/Support: The authors received no financial support for the research, authorship, and/or publication of this article.

Informed Consent: Questionnaires were filled with the participants satisfaction, and informed consent was obtained from the participants in this study.

\section{References}

1. Ashktorab T, Tahmasbi S, Ebadi A, Alavi Majd H. Professional socialization from Iranian nurses experiences. Middle East J Sci Res. 2013;17(7):869-76. 
2. Pai HC, Cheng H, Huang Y. Factors that Influence Professional Socialization in Nursing Students A Multigroup Analysis. Research Square. 2020;Preprint. doi: 10.21203/rs.3.rs-40393/v1.

3. Salisu WJ, Dehghan Nayeri N, Yakubu I, Ebrahimpour F. Challenges and facilitators of professional socialization: A systematic review. Nurs Open. 2019;6(4):1289-98. doi: 10.1002/nop2.341. [PubMed 31660155]. [PubMed Central: PMC6805274].

4. de Swardt HC, van Rensburg GH, Oosthuizen MJ. Supporting students in professional socialisation: Guidelines for professional nurses and educators. Int J Africa Nurs Sci. 2017;6:1-7. doi: 10.1016/j.ijans.2016.11.002.

5. Nikbakht-Nasrabadi A, Parsayekta Z, Seif H, Rasoolzade N. [Experiences of professionalization of nurses at the beginning of entry to clinical nursing phase in Iran]. Hayat. 2006;10(82):3-13. Persian.

6. Bishive Moghaddam S, Mousavi S, MajdeTeimouri Z, Ghanbari Khanghah A, Kazemnezhad LE. [Survey of nursing students professional socialization in the Guilan University of Medical Sciences].J Holist Nurs Midwifery. 2016;26(2):19-28. Persian.

7. Jang S. Study on the Subjectivity of Nursing Students' Perception of Professional. Annals of RSCB. 2021;25(1):1745-56.

8. Quinton WJ. So close and yet so far? Predictors of international students' socialization with host nationals. Int J Intercult Relat. 2020;74:716. doi: 10.1016/j.ijintrel.2019.10.003.

9. Mruk CJ. Self-esteem research, theory, and practice: Toward a positive psychology of self-esteem. New York, USA: Springer Publishing Company; 2006.

10. Seery MD, Quinton WJ. Targeting Prejudice. Soc Psychol Personal Sci. 2015;6(6):677-84. doi: 10.1177/1948550615575756.

11. Mooney M. Professional socialization: The key to survival as a newly qualified nurse. Int J Nurs Pract. 2007;13(2):75-80. doi: 10.1111/j.1440172X.2007.00617.x. [PubMed: 17394514].

12. Moradi Y, Mollazadeh F, Jamshidi H, Tayefeh T, Zaker MR, Karbasi F. Outcomes of professional socialization in nursing: A systematic review. J Pharm Sci Res. 2017;9(12):2468-72.

13. Choi J, Ha N. The relationship among image of nurses, self esteem and professional socialization in nursing students. J Korean Acad Nurs Adm. 2009;15(1):54-63.

14. Shahim A, Lotfi M, Rahmani A. [Professional socialization of nursing graduates of Tabriz University of Medical Sciences]. Nursing and Midwifery Journal. 2011;5(20):19-25. Persian.

15. Chao GT, O'Leary-Kelly AM, Wolf S, Klein HJ, Gardner PD. Organizational socialization: Its content and consequences. J Appl Psychol. 1994;79(5):730-43. doi: 10.1037/0021-9010.79.5.730.

16. Rosenberg M. Rosenberg Self-Esteem Scale. Washington, USA: APA PsycTests; 2011. doi: 10.1037/t01038-000.

17. Ghofrani Kelishami F, Sadoogiasl A, Izadi A, Mohamadkhani Ghiasvand A, Jahani R, Nasiri M. [The Relationship between Self-Confidence of Nursing Students and their Attitude towards a Nursing Career]. Iran J Nurs Res. 2018;12(6):58-64. Persian. doi:10.21859/ijnr-12068.

18. Rajabi G, Buhlul N. [Assess the reliability and validity of rosenberg self-esteem scale in first year Students of Shahid Chamran University]. Educ Psychol Res. 2006;3(2):33-48. Persian.

19. Pai HC, Huang YL, Cheng HH, Yen WJ, Lu YC. Modeling the relationship between nursing competence and professional socialization of novice nursing students using a latent growth curve analysis. Nurse Educ Pract. 2020;49:102916. doi: 10.1016/j.nepr.2020.102916. [PubMed: 33197708].

20. Noohi E, Ildarabadi E, Fakhrbarati M. Relationship between Professional Confidence and Professional Socialization among Nursing Students: A cross-sectional study. La Prensa Medica Argentina. 2020;106(5). doi: 10.47275/0032-745x-231.

21. Seada A, Fathi Sleem W. Professional socialization process and acquisition of professional nursing values among undergraduate nursing students. Am J Sci. 2012;8(4):678-83.

22. Safari Y, Yoosefpour N. Data for professional socialization and professional commitment of nursing students - A case study: Kermanshah University of Medical Sciences, Iran. Data Brief. 2018;21:2224-9. doi: 10.1016/j.dib.2018.11.088. [PubMed: 30555859]. [PubMed Central: PMC6276542]

23. Moradi D, Karami M, Ghanei Gheshlagh R, Nemati M, Dehvan F. Evaluation of the relationship between self-esteem and academic success in nursing students of Kurdistan university of medical sciences, Sanandaj, Iran in 2018. S J Nursing Midwifery and Paramedical Faculty. 2018;4(2):71-8.

24. Alizadeh S, Namazi A, Kouchakzadeh TS. [A Comparative Study of selfesteem in nursing and midwifery students of Islamic Azad University of Rasht and its correlation with academic success]. J Nurs Educ. 2016;4(4 (14)):17-25. Persian.

25. Azizi M, Khamseh F, Rahimi A, Barati M. [The relationship between self-esteem and depression in nursing students of a selected medical university in Tehran]. Iran J Psychiatry Nurs. 2013;1(1):28-34. Persian.

26. Huang C, Dong N. Factor Structures of the Rosenberg Self-Esteem Scale. Eur J Psychol Assess. 2012;28(2):132-8. doi: 10.1027/10155759/a000101.

27. Aboalshamat K, Jawhari A, Alotibi S, Alzahrani K, Al-Mohimeed H, Alzahrani M, et al. Relationship of self-esteem with depression, anxiety, and stress among dental and medical students in Jeddah, Saudi Arabia. Int J Med Dent. 2017;4(2):61-8. doi:10.18320/jimd/201704.0261.

28. Valizadeh L, Zirak M, Parizad N. [Barriers to professional socialization in nursing: An integrative review].J Nurs Educ.2016;5(2 (16)):57-65. Persian.

29. Robins RW, Tracy JL, Trzesniewski K, Potter J, Gosling SD. Personality Correlates of Self-Esteem. I Res Pers. 2001;35(4):463-82. doi: 10.1006/jrpe.2001.2324. 
Table 4. The Degree of Professional Socialization and Self-Esteem According to Some Demographic Characteristics ${ }^{\mathrm{a}}$

\begin{tabular}{|c|c|c|}
\hline Variables & Professional Socialization & Self-Esteem \\
\hline \multicolumn{3}{|l|}{ Gender } \\
\hline Male & $175.21 \pm 15.73$ & $6.12 \pm 4.69$ \\
\hline Female & $174.70 \pm 18.10$ & $5.35 \pm 5.34$ \\
\hline Pvalue & 0.88 & 0.34 \\
\hline \multicolumn{3}{|l|}{ Marital status } \\
\hline Single & $176.02 \pm 20.18$ & $5.45 \pm 5.23$ \\
\hline Married & $167.40 \pm 12.41$ & $6.90 \pm 4.03$ \\
\hline Pvalue & 0.05 & 0.21 \\
\hline \multicolumn{3}{|l|}{ Current student residence } \\
\hline Living with family & $174.50 \pm 20.43$ & $5.72 \pm 5.02$ \\
\hline Dormitory & $174.25 \pm 18.31$ & $5.45 \pm 5.34$ \\
\hline Student house & $188.00 \pm 19.19$ & $7.00 \pm 3.28$ \\
\hline Pvalue & 0.24 & 0.76 \\
\hline \multicolumn{3}{|l|}{ Academic year } \\
\hline First & $174.84 \pm 21.51$ & $4.80 \pm 5.68$ \\
\hline Second & $175.17 \pm 16.18$ & $6.04 \pm 4.74$ \\
\hline Third & $175.45 \pm 23.30$ & $5.71 \pm 5.76$ \\
\hline Forth & $173.97 \pm 16.86$ & $6.31 \pm 4.39$ \\
\hline Pvalue & 0.99 & 0.51 \\
\hline \multicolumn{3}{|c|}{ Being employed while studying } \\
\hline Yes & $180.07 \pm 16.12$ & $5.23 \pm 5.68$ \\
\hline No & $174.43 \pm 19.76$ & $5.68 \mathrm{v} 5.06$ \\
\hline Pvalue & 0.31 & 0.75 \\
\hline \multicolumn{3}{|l|}{ Role model } \\
\hline \multicolumn{3}{|l|}{ Theoretical teachers } \\
\hline Yes & $174.05 \pm 17.48$ & $6.00 \pm 4.64$ \\
\hline No & $175.24 \pm 20.42$ & $5.49 \pm 5.30$ \\
\hline Pvalue & 0.72 & 0.55 \\
\hline \multicolumn{3}{|l|}{ Clinical instructors } \\
\hline Yes & $175.08 \pm 18.55$ & $5.61 \pm 5.29$ \\
\hline No & $174.61 \pm 20.85$ & $5.69 \pm 4.87$ \\
\hline Pvalue & 0.87 & 0.92 \\
\hline \multicolumn{3}{|l|}{ Ward nurses } \\
\hline Yes & $173.42 \pm 18.36$ & $5.32 \pm 5.35$ \\
\hline No & $175.42 \pm 20.11$ & $5.79 \pm 5.02$ \\
\hline Pvalue & 0.54 & 0.58 \\
\hline \multicolumn{3}{|l|}{ Classmates } \\
\hline Yes & $176.80 \pm 19.01$ & $7.20 \pm 2.28$ \\
\hline No & $174.81 \pm 19.59$ & $5.60 \pm 5.16$ \\
\hline Pvalue & 0.82 & 0.49 \\
\hline \multicolumn{3}{|c|}{ Factors influencing the choice of nursing } \\
\hline \multicolumn{3}{|c|}{ Acceptance in the field } \\
\hline Yes & $171.81 \pm 16.44$ & $4.85 \pm 5.46$ \\
\hline No & $177.52 \pm 21.58$ & $6.33 \pm 4.69$ \\
\hline Pvalue & 0.12 & 0.01 \\
\hline \multicolumn{3}{|l|}{ Career future } \\
\hline Yes & $172.24 \pm 20.26$ & $5.10 \pm 5.37$ \\
\hline
\end{tabular}




\begin{tabular}{|c|c|c|}
\hline No & $177.21 \pm 18.64$ & $6.13 \pm 4.83$ \\
\hline Pvalue & 0.10 & 0.19 \\
\hline \multicolumn{3}{|c|}{ Suggestions from others } \\
\hline Yes & $174.08 \pm 14.96$ & $7.28 \pm 5.06$ \\
\hline No & $175.02 \pm 20.26$ & $5.36 \pm 5.07$ \\
\hline Pvalue & 0.82 & 0.08 \\
\hline \multicolumn{3}{|l|}{ Interest } \\
\hline Yes & $182.54 \pm 19.03$ & $6.37 \pm 3.96$ \\
\hline No & $171.28 \pm 19.77$ & $5.30 \pm 5.54$ \\
\hline Pvalue & $<0.001$ & 0.21 \\
\hline \multicolumn{3}{|c|}{$\begin{array}{l}\text { Having information about the field before } \\
\text { entering the university }\end{array}$} \\
\hline Yes & $176.94 \pm 17.01$ & $5.92 \pm 4.51$ \\
\hline No & $171.23 \pm 23.01$ & $5.16 \pm 6.00$ \\
\hline Pvalue & 0.07 & 0.35 \\
\hline \multicolumn{3}{|c|}{$\begin{array}{l}\text { Adaptation of the field to the ideas after } \\
\text { entering the university }\end{array}$} \\
\hline Yes & $179.80 \pm 18.09$ & $6.72 \pm 4.41$ \\
\hline No & $171.63 \pm 19.83$ & $4.94 \pm 5.41$ \\
\hline Pvalue & 0.008 & 0.02 \\
\hline
\end{tabular}

${ }^{\mathrm{a}}$ Values are expressed as mean $\pm \mathrm{SD}$. 